\title{
Vittalle
}

\section{Intubação endotraqueal e via aérea cirúrgica}

\author{
Marina Ilha de Azambuja, Karine Cristina Ghiggi, Miguel Angelo Martins de Castro \\ Junior $^{*}$
}

Faculdade de Medicina, Universidade Federal do Rio Grande, Rio Grande, RS, Brasil

Palavras-chave:

Intubação intratraqueal;

Manuseio das vias aéreas;

Traqueostomia.

Keywords:

Airway management;

Intubation, intratracheal;

Tracheostomy.

\section{RESUMO}

A via aérea é fundamental à vida e constitui prioridade no atendimento ao paciente grave e em situações de emergência. Este capítulo abordará importantes conceitos da intubação endotraqueal e da obtenção de via aérea cirurgicamente e sua aplicabilidade prática.

Endotracheal intubation and surgical airway

\section{ABSTRACT}

The airway is fundamental for life and it is a priority in patient care and in emergency situations. This chapter will describe important concepts of endotracheal intubation and surgical airway and their practical applicability.

\section{Introdução}

Este capítulo objetiva a introdução de conceitos sobre as situações médicas que exigem a garantia da via aérea, pois o pescoço e o terço médio da face são regiões comumente expostas a traumas e acidentes que, muitas vezes, levam à obstrução das vias aéreas e até mesmo à asfixia. O texto foi baseado numa revisão bibliográfica atualizada, da qual foram extraídas as informações mais pertinentes ao estudo prático.

Inicialmente será abordada a intubação endotraqueal, considerando as suas indicações, materiais, técnica e possíveis complicações. A seguir, dispomos de informações sobre via aérea cirúrgica, com ênfase para as situações em que isso se torna necessário no manejo de vias aéreas difíceis.

\section{Intubação endotraqueal}

A intubação endotraqueal, normalmente realizada via oro-traqueal, é indicada em qualquer situação que exija um controle definitivo da via aérea do paciente (Quadro 1). Está indicado como parte do atendimento do paciente crítico com doença ou lesões multissistêmicas, em emergências (por exemplo, em parada cardiorrespiratória) e em pacientes com rebaixamento do sensório que tem pontuação menor ou igual a 8 na Escala de Coma de Glasgow (1).

\footnotetext{
* Autor correspondente: miguelacjr@ hotmail.com (Castro Jr, M.A.M.)
} 
Quadro 1 - Indicações de via aérea definitiva.

\section{Necessidade de proteção da via aérea Necessidade de ventilação ou oxigenação}

\begin{tabular}{|c|c|}
\hline Fraturas maxilofaciais graves & $\begin{array}{l}\text { Movimentos respiratórios inadequados: } \\
\text { - Taquipneia } \\
\text { - Hipóxia } \\
\text { - Hiperapnia } \\
\text { - Cianose }\end{array}$ \\
\hline $\begin{array}{l}\text { Risco de obstrução } \\
\text { - Hematoma cervical } \\
\text { - Lesão de traqueia ou laringe } \\
\text { - Estridor }\end{array}$ & $\begin{array}{l}\text { Hemorragia maciça e necessidade de } \\
\text { reposição volêmica. }\end{array}$ \\
\hline $\begin{array}{l}\text { Risco de aspiração } \\
\text { - Sangramento } \\
\text { - Vômitos }\end{array}$ & $\begin{array}{l}\text { Trauma cranioencefálico contuso grave, } \\
\text { com necessidade de hiperventilação por } \\
\text { um período, se houver piora neurológica. }\end{array}$ \\
\hline Inconsciência & $\begin{array}{l}\text { Apneia: } \\
\text { - Paralisia neuromuscular } \\
\text { - Inconsciência }\end{array}$ \\
\hline
\end{tabular}

Fonte: Adaptado de ATLS, 2018 (1).

O comprometimento das vias aéreas pode se manifestar de forma súbita ou progressiva. Em pacientes com rebaixamento do nível de consciência, a patência da via aérea deve ser estabelecida rapidamente. É fundamental, inicialmente, a inspeção da via aérea para afastar a presença de corpos estranhos, vômitos, acúmulo de saliva ou sangue, os quais devem ser removidos ou aspirados.

A principal contraindicação para intubação oro-traqueal por laringoscopia direta é transecção parcial da traqueia. Outra condição é a cervical instável por lesão da coluna vertebral, que não contraindica a intubação, entretanto deve ser feita a estabilização da cervical, em linha média, durante o procedimento por um assistente que a mantém em posição neutra.

\subsection{Material necessário:}

- Luvas de procedimento;

- Óculos e máscaras de proteção;

- Sistema de aspiração (sonda de aspiração conectada no vácuo);

- Máscara com ambu ligada à fonte de oxigênio $\left(\mathrm{O}_{2}\right), 12$ a 15 litros/minuto;

- Tubos endotraqueais;

- $\quad$ Seringa de $10 \mathrm{ml}$;

- $\quad$ Fita de fixação do tubo;

- Estetoscópio;

- Laringoscópios com lâmina adequada;

- $\quad$ Detector de dióxido de carbono $\left(\mathrm{CO}_{2}\right)$ - Capnógrafos - (se disponível);

- Introdutor de Tubo Traqueal Eschmann (ITTE) - conhecido como guia rígido (se disponível).

2.1.1 Capnografia: Corresponde à informação da mensuração de $\mathrm{CO}_{2}$ expirado, expresso num gráfico em função do tempo ou volume expirado (Figura 1). O gás exalado pelo paciente passa por uma câmara, na qual recebe radiação infravermelha. Assim, a luz é absorvida em diferentes intensidades e a partir desses dados é possível estimar o valor da pressão parcial de $\mathrm{CO}_{2}$. 


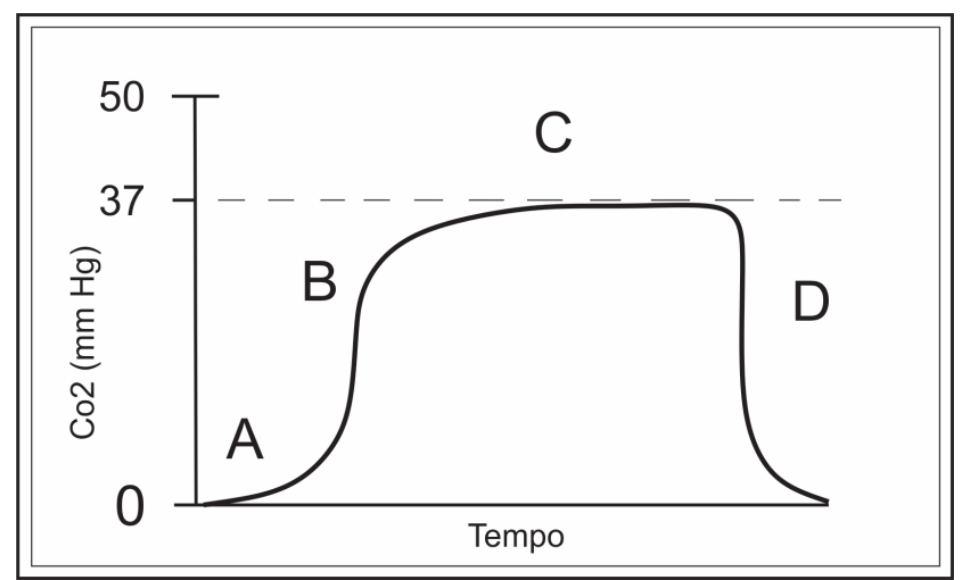

Figura 1 - Capnografia normal.

Fonte: Adaptado de Reich, 2011 (2).

A capnografia normal é dividida em 4 fases:

A. Linha de base: que representa inspiração, em que normalmente não há $\mathrm{CO}_{2}$;

B. Ascenção expiratória de $\mathrm{CO}_{2}$ : quando ocorre a alteração íngreme de exalação de $\mathrm{CO}_{2}$, em indivíduos normais;

C. Platô alveolar: após a liberação do ar pobre em $\mathrm{CO}_{2}$ das vias aéreas superiores (chamado de "espaço morto anatômico") não há trocas gasosas e, portanto, não há $\mathrm{CO}_{2}$, esse ar é substituído pelo ar alveolar, repleto de $\mathrm{CO}_{2}$;

D. Descenso inspiratório: substituição do ar alveolar pela mistura de gás fornecida ao paciente.

A detecção de $\mathrm{CO}_{2}$ no gás expirado pelos capnógrafos é um método confiável para a confirmação do correto posicionamento de um tubo traqueal (2). Vale ressaltar, que indivíduos que foram ventilados com máscara facial ou laríngea antes da intubação, podem apresentar $\mathrm{CO}_{2}$ no estômago. Portanto, para que se constate a intubação endotraqueal deve ocorrer a consistência e a recorrência do $\mathrm{CO}_{2}$ no gás expirado.

2.1.2. Os dois tipos principais de lâminas são as Lâmina de Macintosh, que é curva, e a Lâmina de Miller, que é reta; estão disponíveis em diversos tamanhos, assim a escolha da lâmina depende da experiência do operador e das preferências conforme o biotipo do paciente (3).

As lâminas número 3 e 4 de Macintosh - Curvas, e as número 2 e 3 de Miller - Retas, são as mais usadas em pacientes adultos.

2.1.3. Os tubos endotraqueais são dimensionados de acordo com o diâmetro interno do tubo; normalmente os tubos de: $7.0 \mathrm{~mm}, 7.5 \mathrm{~mm}$ e $8.0 \mathrm{~mm}$ são os mais apropriados para a maioria dos adultos.

O tamanho de tubo apropriado para crianças pode ser determinado através da fórmula: ([idade em anos +16$] \div 4=$ tamanho do tubo).

Os tubos podem ter balão para insuflar ou não. O balão do tubo garante a estabilização do tubo no local apropriado e impede o vazamento de ar pelas laterais, criando uma vedação entre o tubo e o lúmen traqueal. Este selo é o que impede o vazamento de ar e a aspiração de conteúdo gástrico.

\subsection{Preparação}


- Verificar se todos os aparelhos e equipamentos estão funcionando adequadamente e prontamente acessíveis (verificar o funcionamento da luz do laringoscópio, insuflar o balão do tubo para garantir que não há vazamentos).

- O paciente deve estar monitorizado e com acesso intravenoso.

- Ajustar a altura da cama, de modo que a cabeça fique nivelada com o esterno. A menos que existam contraindicações, deve ser colocado um coxim ou toalha dobrada sob a occipital do paciente. Essa combinação de flexão do pescoço e extensão da cabeça (sniffing position) melhora o alinhamento dos eixos da cavidade oral, faringe e laringe, facilitando a visualização das cordas vocais (3).

- Deve-se pré-oxigenar o paciente através de uma máscara com $100 \%$ de $\mathrm{O}_{2}$ por no mínimo 3 minutos antes da intubação. A pré-oxigenação substitui a mistura de ar ambiente que esta como capacidade funcional residual do paciente por oxigênio. Isto aumenta o intervalo de tempo até a queda da saturação do doente que é hipoventilante ou apneico (4).

Em muitos casos é necessário usar um bloqueador neuromuscular e um sedativo para facilitar a intubação. Estes fármacos relaxam a musculatura e auxiliam na visualização das cordas vocais.

- Sedativo (Quadro 2):

Quadro 2 - Drogas sedativas.

\begin{tabular}{|l|l|l|l|}
\multicolumn{1}{c|}{ Droga } & \multicolumn{1}{c|}{ Dose } & \multicolumn{1}{c|}{ Início } & \multicolumn{1}{c|}{ Duração } \\
\hline Etomidato & $0,3 \mathrm{mg} / \mathrm{kg}$ & 30 a 60 segundos & 3 a 5 minutos \\
\hline Propofol & $0,5-3 \mathrm{mg} / \mathrm{kg}$ & 9 a 50 segundos & 3 a 10 minutos \\
\hline Midazolan & $\begin{array}{l}0,1 \mathrm{a} 0,5 \mathrm{mg} / \mathrm{kg}: \text { comece com } 0,3, \text { caso } \\
\text { necessário repita } 1 / 2 \text { da dose inicial. }\end{array}$ & 3 a 60 segundos & 3 a 10 minutos \\
\hline
\end{tabular}

- $\quad$ Bloqueador neuromuscular (Quadro 3):

Quadro 3 - Bloqueio neuromuscular.

\begin{tabular}{|l|l|l|}
\multicolumn{1}{c|}{$\begin{array}{c}\text { Droga } \\
\text { Succinilcolina }\end{array}$} & \multicolumn{1}{c|}{\begin{tabular}{c}
\multicolumn{1}{c|}{ Dose inicial } \\
mg/kg
\end{tabular}} & $\begin{array}{l}\text { 1 a } 2 \mathrm{mg} / \mathrm{kg} \text {, aplicados entre } 10 \text { e } 30 \\
\text { segundos (procedimentos rápidos) }\end{array}$ \\
\hline Atracúrio & $0,3-0,6 \mathrm{mg} / \mathrm{kg}$ & 0,3 a $0,6 \mathrm{mg} / \mathrm{kg} / \mathrm{h} \mathrm{em} \mathrm{BI}$ \\
\hline Pancurônio & $0,06-0,1 \mathrm{mg} / \mathrm{kg}$ & 0,01 a $0,03 \mathrm{mg} / \mathrm{kg} / \mathrm{min} \mathrm{em} \mathrm{BI}$ \\
\hline
\end{tabular}

Nos casos de necessidade de obtenção rápida de via aérea em pacientes que apresentam reflexos da via aérea preservados, recomenda-se utilizar a Indução em Sequência Rápida, que é realizado por agente farmacológico anestésico (barbitúricos ou anestésicos voláteis) e um relaxante muscular de ação rápida. A seguir, as drogas mais comuns encontradas nas enfermarias, mostrando a diluição, dose e forma de aplicação (Quadro 4): 
Quadro 4 - Apresentação e aplicação das principais drogas.

\begin{tabular}{|c|c|c|}
\hline Drogas $\rightarrow$ & Midazolan & Succinilcolina \\
\hline Apresentação & $0,15 \mathrm{mg} / \mathrm{mL}$. & 500 mg pó. \\
\hline Diluição & $\begin{array}{l}\text { Diluir os } 3 \mathrm{~mL} \text { da ampola em } 12 \mathrm{~mL} \text { de } \\
\text { Água Destilada (AD). Assim, teremos } \\
15 \mathrm{~mL} \text { com } 15 \mathrm{mg}=1 \mathrm{mg} / 1 \mathrm{~mL} \text {. }\end{array}$ & $\begin{array}{l}\text { Diluir } 500 \mathrm{mg} \text { em } 10 \mathrm{ml} \text { de AD. Assim, } \\
\text { teremos a cada } 1 \mathrm{~mL}=50 \mathrm{mg} \text { (solução } \\
\text { inicial). Reservar } 2 \mathrm{~mL}(100 \mathrm{mg} \text { ) da } \\
\text { diluição. Diluir os } 2 \mathrm{~mL} \text { em } 8 \mathrm{~mL} \text { de } \\
\text { AD. Dessa diluição teremos } 10 \mathrm{~mL}= \\
100 \mathrm{mg} \text {, ou seja, } 1 \mathrm{~mL}=10 \mathrm{mg} \text { (solução } \\
\text { final). }\end{array}$ \\
\hline Dose / Aplicação & $\begin{array}{l}\text { Recomenda-se administrar } 5 \mathrm{~mL}(5 \mathrm{mg}) \text {, } \\
\text { EV, observando a resposta, por até } 3 x \\
\text { (15 mg no total). }\end{array}$ & $\begin{array}{l}\text { A dose inicial preconizada para intuba- } \\
\text { ção é } 1 \mathrm{mg} / \mathrm{kg}(\mathrm{p} \text {. ex.: indivíduo com } 70 \\
\mathrm{kg} \text {, dose: } 70 \mathrm{mg}=7 \mathrm{~mL}, \mathrm{EV} \text {, da solução } \\
\text { final). }\end{array}$ \\
\hline
\end{tabular}

Se há a indicação de usar esses fármacos, deve-se considerar a dificuldade de intubar o paciente. Essa dificuldade pode ser avaliada pelo método mnemônico LEMON (1):

L: Localize externamente: boca ou mandíbula pequena, prognatismo e trauma facial;

E: Examine as distâncias na regra do 3-3-2;

- A distância entre os dentes incisivos deve ser de pelo menos 3 dedos (3);

- A distância entre o osso hióide e o mento deve ser de pelo menos 3 dedos (3);

- A distância entre a proeminência tireoidiana e o assoalho da boca deve ser de pelo menos 2 dedos (2);

M: Mallampati: visualização das estruturas laríngeas; quanto maior o grau do Mallampati, menos se observa as estruturas e, consequentemente, torna a intubação mais difícil (Figura 2);

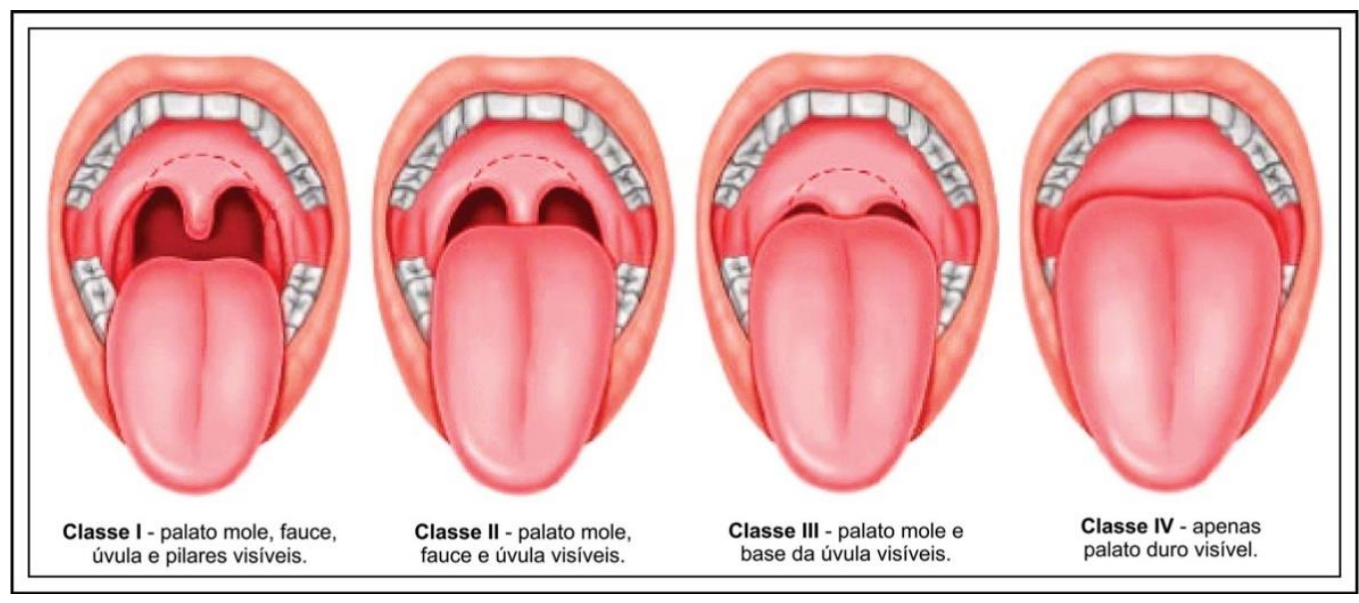

Figura 2 - Classificação Mallampati.

O: Obstrução: qualquer condição que leve a obstrução da via aérea tornará a laringoscopia e a ventilação difíceis; essas situações incluem epiglotite, abscesso peritonsilar e trauma;

N: No peito encoste o queixo - Mobilidade cervical: a mobilidade do pescoço é importante para a intubação ser bem-sucedida, ela é avaliada ao solicitar que o paciente flexione o queixo no peito e, após, estender como se fosse olhar para cima. 


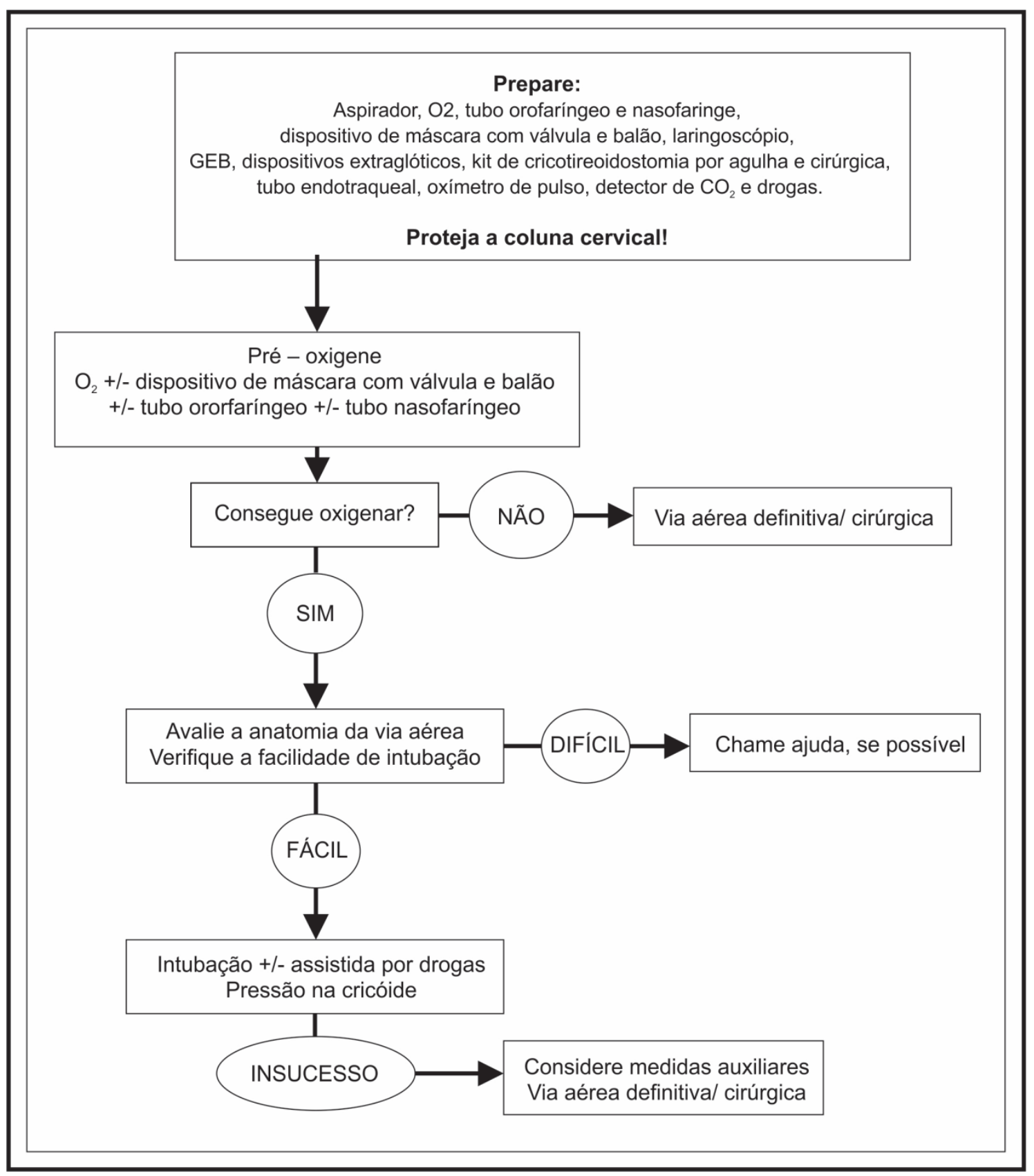

Figura 3 - Esquema para abordagem de via aérea.

Fonte: Adaptado de ATLS, 2018 (1).

\section{Técnica:}

- Posicione seu corpo de modo que seus olhos estejam suficientemente longe para ter uma visão binocular.

- Segure o laringoscópio com a mão esquerda e abra a boca do paciente com a mão direita; insira a lâmina do laringoscópio à direita da língua do paciente, devagar mova a lâmina para o centro da boca, empurrando a língua para a esquerda (Figura 4).

- Avance lentamente a lâmina até encontrar a epiglote. Se estiver usando uma lâmina curva, coloque a ponta na valécula epiglótica; mas, se estiver usando a lâmina reta, coloque a ponta da lâmina posterior para a epiglote.

- Com a ponta da lâmina posicionada corretamente, levante o laringoscópio para cima e para frente num ângulo de 45 graus para expor as cordas vocais (3). A força deve ser feita no sentido de elevação ao longo do eixo da alça do laringoscópio, na direção do 
teto, sobre os pés do paciente.

- Enquanto se segura o tubo endotraqueal na sua mão direita, mantenha a visão das cordas vocais; insira o tubo endotraqueal no lado direito da boca do paciente (3).

- Passe o tubo através das cordas vocais até o balão desaparecer na traqueia.

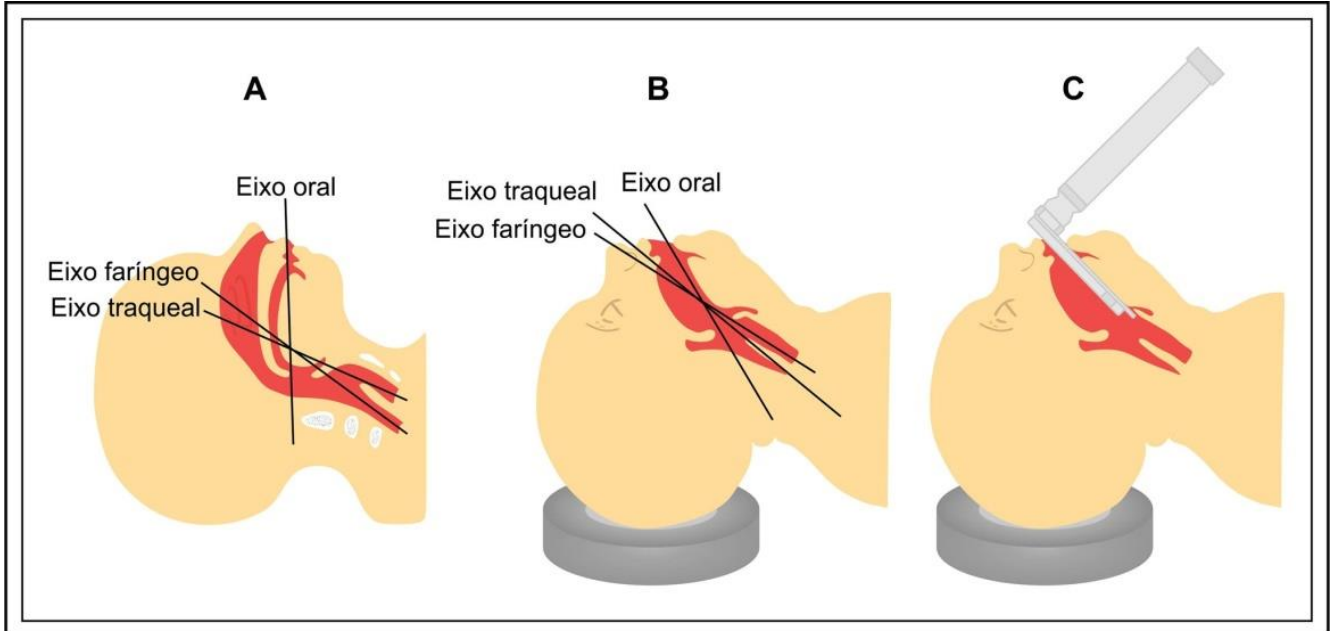

Figura 4 - Eixos e alinhamentos.

- Insuflar o balão do tubo com aproximadamente $10 \mathrm{ml}$ de ar através de uma seringa. Isso deve ser necessário para não ocorrer vazamento de ar e exercer pressão mínima na parede traqueal (1).

- Iniciar a ventilação com pressão positiva; o posicionamento adequado do tubo na traqueia é sugerido, porém não confirmado, pela ausculta de murmúrio vesicular em ambos campos pulmonares e pela ausência de ausculta de borborigmos no epigástrio (3).

Deve-se primeiro auscultar o epigástrico, a ausculta de borborigmos na inspiração denota que o tubo está no esôfago e deve ser trocado e reposicionado. Se não for auscultado os borborigmos, ausculta-se o hemitórax esquerdo na linha axilar e, após, o direito, também na linha axilar. Vale ressaltar que por questões anatômicas, o brônquio fonte direito tem mais chance de estar seletivo com o tubo; quando se ausculta murmúrio vesicular no lado direito e não no esquerdo, deve-se tracionar o tubo em alguns centímetros e auscultar novamente para confirmar o murmúrio vesicular bilateralmente.

- A extremidade do tubo endotraqueal deve estar na traqueia média, ou seja, 3 a $7 \mathrm{~cm}$ acima da carina (3). Para adultos de porte médio, pode-se levar em conta a regra prática de alinhar a marcação de $22 \mathrm{~cm}$ no tubo com os dentes da frente do paciente. Para crianças, pode ser usada a fórmula: Profundidade do tubo em $\mathrm{cm}=[$ (idade da criança em anos) $\div 2]+12$;

- Idealmente deve ser usado o detector de dióxido de carbono (capnógrafo ou detector colorimétrico de $\mathrm{CO}_{2}$ ) para auxiliar na confirmação da intubação correta da via aérea;

- O posicionamento adequando do tubo é confirmado através de radiografia de tórax, uma vez que a intubação esofágica esteja excluída.

- Assim que se obter a confirmação da via aérea corretamente estabelecida, deve-se ligar o sistema na ventilação mecânica.

- Estando o paciente monitorado obrigatoriamente, deve-se avaliar os parâmetros fisiológicos e manter uma frequência respiratória normal, em torno de 16- 20 incursões respiratórias por minuto. 
A complicação mais grave da intubação endotraqueal é a intubação esofágica não reconhecida, que pode levar a hipoxemia, hipercapnia e morte. A laringoscopia pode provocar vômitos e aspiração do conteúdo gástrico, causando pneumonite ou pneumonia. As complicações adicionais incluem: bradicardia, laringoespasmo, broncoespasmo e apneia devido a estimulação faríngea (3).

\section{Via Aérea Cirúrgica (Quadros 5 e 6)}

Acessos cirúrgicos incluem:

- Cricotireoidostomia cirúrgica;

- Traqueostomia.

Quadro 5 - Indicações de via aérea cirúrgica.

\begin{tabular}{|c|}
\hline Principais indicações de via aérea cirúrgica \\
\hline Obstrução por edema de glote \\
\hline Trauma maxilofacial extenso ou cervical \\
\hline Hemorragia orofaríngea grave \\
\hline Anatomia do paciente ser difícil \\
\hline Presença de corpo estranho obstruindo a via aérea \\
\hline Fratura de laringe (somente traqueostomia) \\
\hline
\end{tabular}

Fonte: Adaptado de Hsiao e Pacheco-Fowler, 2008 (5).

Quadro 6 - Contraindicações de via aérea.

\begin{tabular}{|c|}
\hline Principais contraindicações de via aérea cirúrgica \\
\hline Diátese hemorrágica pelo risco de hemorragia incontrolável \\
\hline Infecções na pele \\
\hline Cirurgias em região cervical anterior que modifiquem a anatomia \\
\hline
\end{tabular}

Fonte: Adaptado de Marsico e Marsico, 2010 (6).

\subsection{Cricotireoidostomia}

A cricotireoidostomia é um procedimento de emergência realizado em pacientes com dificuldade respiratória grave, em que as tentativas de intubação endotraqueal falharam ou foram consideradas de risco inaceitável (5).

O procedimento envolve a realização de uma incisão na membrana cricotireóide, (que fica entre as cartilagens da tireóide e cricóide) e inserir um tubo de traqueostomia na traqueia (Figura 5). 


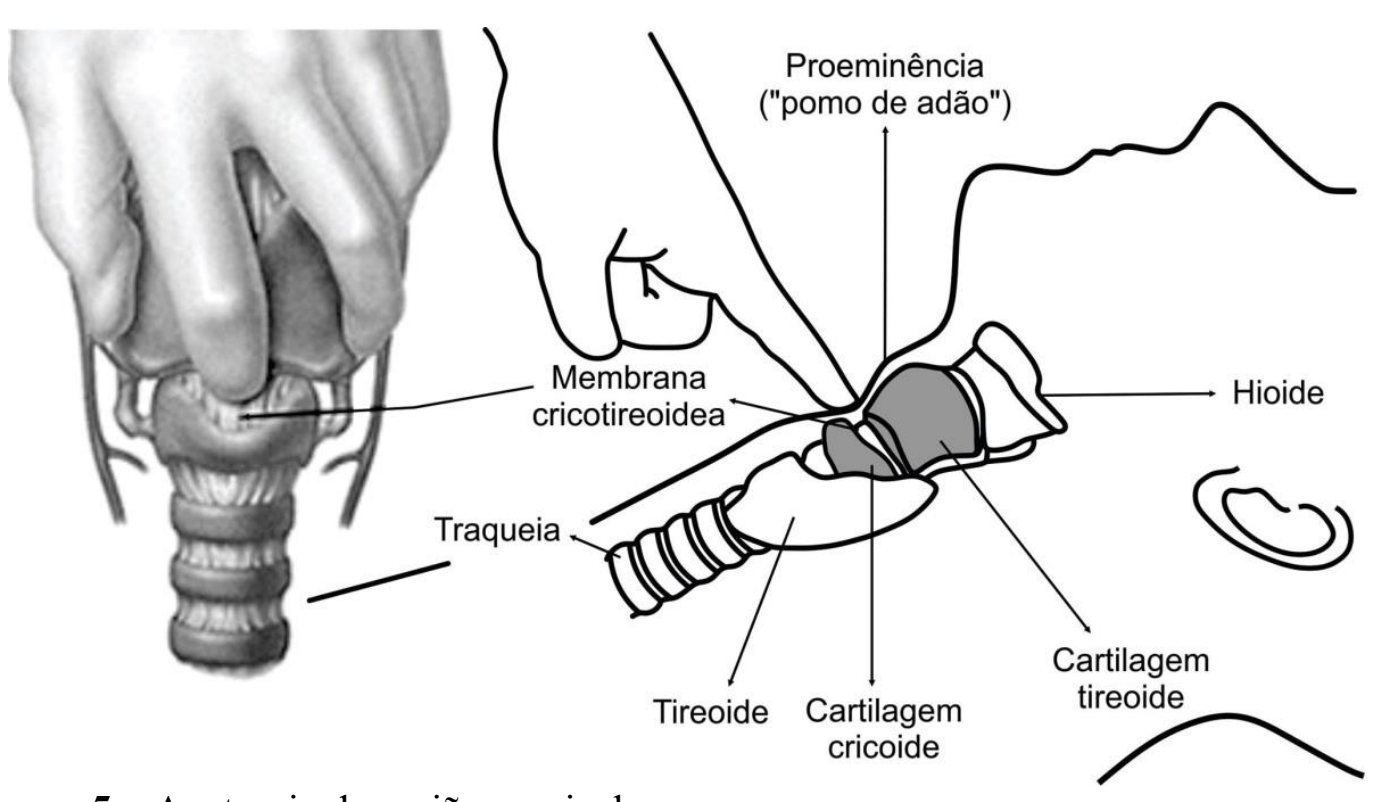

Figura 5 - Anatomia da região cervical.

A cricotireoidostomia cirúrgica é preferível à traqueostomia para a maioria dos doentes que necessitam de uma via aérea cirúrgica de emergência, por ser mais fácil de ser realizada, apresenta menor risco de hemorragia e requer menor tempo para sua execução do que uma traqueostomia.

Um tubo de traqueostomia colocado durante uma cricotireoidostomia pode ser deixado no local por até 72 horas, antes de uma nova intervenção. Devido às potenciais complicações da cricotireoidostomia, como a estenose subglótica e lesão das cartilagens cricóide e tireoide, essa deve ser convertida em traqueostomia, no caso de ser necessário o acesso da via aérea por mais de 72 horas (5).

\subsubsection{Cricotireoidostomia por punção}

Realizada através de inserção de um cateter 14 ou 16 através membrana cricotireoidiana, em situações emergenciais. A cricotireoidostomia por punção permite uma ventilação por corrente pressurizada de oxigênio, a 12 a 15 litros/minuto, por um curto espaço de tempo, aproximadamente 30 a 45 minutos, na frequência (I: E) $=1$ seg: 3 seg.

\subsubsection{Cricotireoidostomia cirúrgica}

Material:

- Luvas estéreis, roupas estéreis, óculos de proteção e máscara de procedimento.

- Solução para a assepsia local e gazes;

- Lidocaína 1 a $2 \%$ com epinefrina;

- $\quad$ Seringa de $6 \mathrm{ml}$ e $10 \mathrm{ml}$;

- Tubo de traqueostomia;

- Bisturi com lâmina 10 ou 11;

- Pinça hemostática curva;

- Material para sutura e amarração.

O tubo de traqueostomia compreende três partes: a cânula externa, que apresenta uma placa de gargalo que se estende aos dois lados, permitindo que o tubo seja preso ao 
pescoço por suturas ou laço de pano (5). A cânula interna, que apresenta a extremidade adaptada para ser ligada ao ambu ou à ventilação mecânica. E o obturador que proporciona uma superfície lisa para guiar a inserção do tubo.

\section{Procedimento:}

- Paciente em posição supina, deve-se realizar a assepsia local;

- Se o paciente estiver acordado, deve-se anestesiar o local;

- Para realizar o procedimento, deve-se estar de pé ao lado direito do paciente;

- Estabilize a laringe com o polegar esquerdo e o dedo médio e use o dedo indicador para palpar a cartilagem da tireoide. Mova o dedo indicador para baixo até palpar a cartilagem cricóide. $\mathrm{O}$ espaço entre as cartilagens tireoide e cricóide é a membrana cricotireoidea e é nesse local se deve incisar (5);

- Use o bisturi para fazer uma incisão vertical de $2,5 \mathrm{~cm}$ através da pele e do tecido subcutâneo. Use a pinça homeostática curva para fazer uma dissecção romba no tecido subcutâneo;

- Em seguida, use o bisturi para fazer uma incisão horizontal através da membrana cricotireoidea. Pode-se sentir um estalo ao entrar na traqueia. Estenda a incisão lateralmente.

Para evitar a perfuração do esôfago, que fica posterior à traqueia, não se deve ultrapassar $1,3 \mathrm{~cm}(1 / 2$ polegada) de profundidade.

- Uma vez que a traqueia é acessada, certifique-se que a lâmina permaneça dentro da incisão, de modo que a comunicação com a traqueia não seja perdida;

- Insira o tubo traqueal na luz;

- Insufle o balão do tubo com uma seringa de $10 \mathrm{ml}$ e conecte o paciente ao sistema de ventilação.

Procure o aumento simétrico do tórax e ausculte ambos os campos pulmonares, procurando sons da respiração, de igual proporção.

Após o procedimento, deve-se obter uma radiografia de tórax para confirmar a colocação do tubo de traqueostomia e uma avaliação cirúrgica para traqueostomia definitiva, se necessário.

As principais complicações da cricotireoidostomia são: perfuração esofágica, enfisema subcutâneo e hemorragias.

A cricotireoidostomia cirúrgica não é recomendada para crianças abaixo de 12 anos, pela possibilidade de lesão da cartilagem cricóide, que é o único suporte circunferencial para a parte superior da traqueia (5).

\section{Traqueostomia}

É o procedimento cirúrgico que consiste na abertura da parede anterior da traqueia, comunicando-a com o meio externo, tornando a via aérea pérvia.

A maioria das traqueostomias é eletiva, restritas aos pacientes que necessitam de via aérea alternativa, prolongada ou permanente, com a finalidade de evitar as complicações da intubação orotraqueal prolongada. 
Quadro 7 - Indicações de traqueostomia.

\begin{tabular}{|c|}
\hline Principais indicações de traqueostomia \\
\hline $\begin{array}{c}\text { Permitir ventilação mecânica em intubações } \\
\text { orotraqueais prolongadas }\end{array}$ \\
\hline Manobra para liberar uma obstrução de via aérea \\
\hline $\begin{array}{c}\text { Permitir higiene pulmonar, incluindo indivíduos com } \\
\text { aspiração laringotraqueal }\end{array}$ \\
\hline $\begin{array}{c}\text { Permitir a ventilação em pacientes com debilidade na } \\
\text { musculatura respiratória por diminuir o espaço morto }\end{array}$ \\
\hline
\end{tabular}

Fonte: Adaptado de Ricz et al., 2011 (7).

A indicação mais comum para realização da traqueostomia (Quadro 7) é a ventilação mecânica prolongada (6). Recomenda-se que a intubação endotraqueal seja convertida em traqueostomia o mais precoce, pois, a partir do décimo dia de intubação o índice de complicações aumenta significativamente ao favorecer o aparecimento de processos inflamatórios laríngeos, granulomas, infecções locais, luxações e artroses de aritenóides, imobilidades de pregas vocais, estenoses glóticas e subglóticas, traqueomalácea e estenoses traqueais. Após o sexto dia de intubação translaríngea são detectadas lesões agudas na laringe em $100 \%$ dos casos (8). Em pacientes adultos gravemente doentes, que necessitam de ventilação, traqueotomia realizada em um estágio inicial (dentro da primeira semana) pode encurtar a duração da ventilação e tempo de internação em terapia intensiva (9).

Vantagens da traqueostomia em relação à intubação orotraqueal $(6,7,9)$

- Previne lesões laríngeas secundárias a intubação prolongada;

- É mais confortável para os pacientes;

- Permite alimentação por via oral e a fala;

- Facilita a mobilização e os cuidados de enfermagem;

- Dispensa ou diminui a sedação, necessária na intubação orotraqueal;

- Facilita e acelera o desmame da ventilação mecânica;

- Permite aspirações traqueais efetivas, limpeza da árvore traqueobrônquica;

- Diminui a incidência de pneumonias;

- Melhora a higiene oral e reduz o trauma na cavidade oral.

Após cinco a sete dias de traqueostomia, já existe um trajeto traqueocutâneo bem estabelecido, o que facilita a reintrodução da cânula e a transferência dos pacientes para unidades de cuidados intermediários (6).

Outros efeitos benéficos sobre a dinâmica respiratória são: diminuição do espaço morto, do esforço respiratório, da resistência das vias aéreas e do aumento da complacência pulmonar, favorecendo assim os pacientes com reserva pulmonar comprometida (6). Além disso, pacientes submetidos à traqueostomia apresentam menos tempo de internação hospitalar (10). 
Contraindicações $(9,11)$ :

- Plaquetopenia e uso de drogas antiplaquetárias;

- Infecção cutânea;

- Cirurgia anterior do pescoço grande que obscurece completamente a anatomia.

Técnica cirúrgica:

Esse procedimento deve ser realizado preferencialmente em um centro cirúrgico, com equipe preparada, com anestesia geral ou local. A escolha da cânula de traqueostomia (metálica ou plástica) deve ser feita antes do procedimento, levando-se em conta as necessidades do paciente.

1. Posição do paciente: o paciente deve ser posicionado em decúbito dorsal horizontal, adotando hiperextensão cervical, utilizando um coxim sob o dorso e rodilha para sustentar a cabeça.

2. Reparos anatômicos: os principais pontos de reparo são: borda inferior da cartilagem tireóide, membrana cricotireoidea, cartilagem cricoide e fúrcula esternal. Por meio da palpação cervical estas estruturas são claramente identificadas.

3. Anestesia: a traqueostomia realizada com anestesia local torna o procedimento mais difícil do que com anestesia geral. A injeção do anestésico local deve ser efetuada mesmo em pacientes sob anestesia geral, já que promove vasoconstrição, facilitando o procedimento e diminuindo a dor pós-operatória (7).

4. Incisão da pele: a incisão da pele pode ser realizada de duas formas: longitudinal ou transversal. A longitudinal ou vertical é a incisão que se inicia desde a borda inferior da cartilagem cricóide, numa extensão de 2 a $3 \mathrm{~cm}$ em direção ao esterno, na linha mediana. É mais fisiológica, pois permite que a cânula de traqueostomia se mova para cima e para baixo até encontrar a posição ideal, evitando trações que pressionem e lesem as paredes traqueais.

A transversal ou horizontal é a incisão localizada na linha média entre a borda inferior da cartilagem cricóide e a fúrcula esternal, é paralela às linhas de tensão da pele do pescoço e, incorpora-se facilmente a outras incisões cervicais. A incisão longitudinal permite acesso à traqueia com menor dissecção de tecidos. Portanto, pelas facilidades encontradas durante o ato cirúrgico, recomenda-se optar pela incisão vertical para realização da traqueostomia (7).

5. Dissecção da musculatura: após incisão da pele com bisturi (lâmina 15), que deverá incluir tecido subcutâneo e eventualmente o músculo platisma, deve-se realizar cuidadosa hemostasia com eletrocautério. A dissecção cuidadosa deste plano geralmente ocorre sem sangramento, exceto quando existe lesão das veias jugulares anteriores que estão paralelas à linha mediana, 1 a $2 \mathrm{~cm}$ lateralmente a ela.

6. Istmo da tireoide: habitualmente a glândula tireoide está sobre o primeiro e segundo aneis traqueais, porém, o terceiro anel está imediatamente caudal à borda inferior do istmo da glândula tireoide. Com dissecção cuidadosa é possível acessar o terceiro anel e aí realizar a traqueostomia. No entanto, quando isso não for possível, o istmo deve ser exposto completamente, decidindo-se, então, pelo seu deslocamento látero- 
superiormente ou pela istmectomia (7).

7. Traquéia: após tratar o istmo da tireoide, podem-se visualizar os anéis traqueais, abrindo-se a fáscia pré-traqueal. A abertura da traqueia deve ser feita do $2^{\circ}$ ao $4^{\circ}$ anel traqueal, preferencialmente no segundo ou terceiro anéis. O primeiro anel deve ser evitado pois pode resultar em lesão da região subglótica da laringe, predispondo a estenose. Abaixo do quarto anel aumenta-se o risco de lesão de estruturas torácicas como pleura e grandes vasos (7).

8. Cânula endotraqueal: a colocação da cânula endotraqueal deve ser cuidadosa para que não ocorram lesões ou sangramentos das estruturas locais, ou mesmo falso trajeto para $o$ mediastino superior. Outro cuidado é introduzi-la perpendicularmente ao pescoço, e somente ao tocar a parede posterior da traqueia, ela deve ser girada e deslizada em direção ao mediastino, evitando assim, falsos trajetos. O diâmetro da cânula utilizada deve ser compatível com a traqueia do paciente. As cânulas podem ser metálicas ou de silicone (plástico). A preferência deve sempre ser dada às metálicas, por serem de mais fácil manuseio em ambiente domiciliar, pois facilitam a higienização e têm menor custo.

Cuidados pós-operatórios: A ferida cirúrgica não deve ser fechada hermeticamente, para que o ar não se acumule no subcutâneo, gerando enfisema subcutâneo. Criteriosa revisão da hemostasia deve ser realizada. A cânula deve ser fixada, amarrando-a em volta do pescoço, por meio de um cadarço; e o curativo consiste de gazes circundando a cânula para absorver pequenos sangramentos e secreção. A primeira troca da cânula só deve ocorrer seguramente a partir do terceiro dia de pós-operatório, quando a fibrose ao redor da cânula promove uma comunicação entre a pele e o orifício traqueal. Formado o trajeto fibroso, a troca da cânula, na maioria das vezes é simples e pode ser feita facilmente pelo próprio paciente ou cuidador.

Neste instante a troca deve ser diária, no entanto a cânula interna deve ser retirada ao menos quatro vezes ao dia para ser lavada, dependendo da quantidade de secreção produzida pelo paciente.

\section{Complicações:}

A complicação mais comum é a hemorragia observada no pós-operatório imediato, seguida pela obstrução da cânula por secreção e o deslocamento da cânula. Outras complicações podem ocorrer: enfisema subcutâneo, lesão traqueal, infecção da ferida, pneumotórax, pneumomediastino, fístula traqueoesofágica, formação de granuloma. Problemas de deglutição podem ocorrer decorrentes de: diminuição da laringe, compressão esofágica e obstrução do balonete do tubo de traqueotomia $(7,9,12)$.

Decanulação:

Critérios para a decanulação da traqueostomia (9):

- Ausência de angústia;

- Estabilidade hemodinâmica;

- Ausência de febre ou infecção ativa;

- $\mathrm{PaCO}_{2}<60 \mathrm{mmHg}$;

- Ausência de delírio ou transtorno psiquiátrico;

- Exame endoscópico normal ou revelação estenótica de lesão ocupando <30\% da via aérea;

- Deglutição adequada;

- Capaz de expectorar. 
Após a deflação do balonete da traqueostomia, um dedo enluvado oclui a abertura do tubo e observa-se o paciente quanto a sinais objetivos de dificuldade respiratória. Em caso de problemas, paciente retorna à respiração através do tubo de traqueotomia e realiza um exame endoscópico para verificar a obstrução das vias aéreas superiores. Se não houver lesões, deve-se considerar se o tubo não é muito grande e tentar novamente após a troca do tubo (9).

Caso não haja problemas, o tubo pode ser removido e a abertura coberta com curativos estéreis. A ferida cicatriza espontaneamente em 10 dias na maioria dos casos (9).

\section{Referências}

1. American College of Surgeons. Advanced Trauma Life Support (ATLS). Chigaco: The Committee on Trauma, 2018.

2. Reich DL. Monitoring in Anesthesia and Perioperative Care. Cambridge University Press, 2011.

3. Kabrhel C, Thomsen TW, Setnik GS, Walls RM. Orotracheal Intubation. N Eng J Med 2007; 356(17): e15.

4. Tallo SF, Guimarães HP, Lopes RD, Lopes AC. Intubaçao orotraqueal e a técnica de sequencia rápida: uma revisão para o clínico. Rev Bras de Clin Med 2011; 9(3): 211-7.

5. Hsiao J, Pacheco-Fowler V. Cricothyroidotomy. N Eng J Med 2008; 358(22): e25.

6. Marsico PS, Marsico GA. Traqueostomia. Pulmão RJ 2010; 19(2): 24-32.

7. Ricz HMA, Filho Filho FVM, Conti de Freitas LC, Mamede RCM. Traqueostomia. Medicina (Ribeirão Preto) 2011; 44(1): 63-9.

8. Whited RE. A prospective study of laryngotracheal sequelaein long-term intubation. Laryngoscope 1984; 94(3):367-77.

9. Leyn P, Bedert L, Delcroix M, Depuydt P, Lauwers G, Sokolov Y, et al. Tracheotomy: clinical review and guidelines. Eur J Cardio-Thorac Surg 2007; 32 (3): 412-21.

10. Duran M, Abdullayev R, Çömlekçi M, Süren M, Bülbül M, Aldemir T. Comparação de traqueotomia percutânea precoce e tardia em unidade de terapia intensiva para adultos. Braz J Anest 2014; 64(6): $438-42$.

11. Saad Jr R, Araraki JSO, Gonçalves R, Polonio IB. Ligas Acadêmicas de Pneumologia e Cirurgia Torácica do Estado de São Paulo. Editora Atheneu, 2014.

12. Kansu L, Aydin E, Avci S. A percutaneous tracheotomy complication: tracheal stenosis: case report. Turkiye Klinikleri J Med Sci 2008; 28: 773-7 